as it happens in IUGR. To assess changes in neural connectivity in the hippocampus in IUGR animals, the hippocampus synaptic network has been analysed through three different synaptic proteins, Postsynaptic Density Protein 95 (PSD95), Synaptophysin and Synaptosome-associated Protein of $25 \mathrm{KDa}$ (SNAP25).

Methods IUGR was induced by meso-ovarian vessels' cauterization in pregnant rats. Sham surgery was performed in control animals. The pups were divided into: Control, Ischemic and IUGR (birth weight $<2$ SD). 25 days after birth, animals were subjected to an aquatic learning test. At day 35, they were sacrificed. Synaptic protein levels were analysed by immunochemistry staining and Western blotting.

Results There were differences in the learning outcomes between Control, Ischemic and IUGR animals. The analysis of PSD95, showed a gradual staining reduction from Controls to Ischemic to IUGR. There were no differences between groups in Synaptophysin inmunostaining. The intensity of SNAP25 staining was lower in Ischemic and IUGR than in Controls. These results were corroborated by western blot analysis.

Conclusions IUGR animals displayed reduced protein levels of PSD95 and SNAP25 in the hippocampus with respect to Control animals, suggesting a decrease in functional synapses.

\section{OUALITY OF GENERAL MOVEMENTS AFTER TREATMENT WITH LOW-DOSE DEXAMETHASONE IN PRETERM INFANTS AT RISK FOR BRONCHOPULMONARY DYSPLASIA}

doi:10.1136/archdischild-2012-302724.1256

MM Hitzert, ME van der Laan, AM Roescher, AF Bos. Division of Neonatology, Beatrix Children's Hospital, University Medical Center Groningen, Groningen, The Netherlands

Background Postnatal dexamethasone (DXM) is widely used to treat preterm infants at risk for bronchopulmonary dysplasia. Previously, it was reported that high-dose DXM leads to deteriorated quality of general movements (GMs). We determined neurological functioning in infants after low-dose DXM treatment, assessed by the GM-quality until three months post term.

Methods We included preterm infants, admitted to our NICU between 2010-2012 and treated with DXM (starting dose $0.25 \mathrm{mg}$ / $\mathrm{kg} / \mathrm{d}$ ). GM-quality was assessed before (day 0), during and after treatment until three months post term. We determined the change in GM-quality by comparing the GM-quality of day 0 with the GMquality of the last video recording. Additionally, we calculated a motor optimality score (MOS), ranging from 8 (low optimality) to 18 (high optimality).

Results Sixteen infants were included [median GA 26.9 wks (25.0-29.7); BW 800 g (620-1665)]. Before treatment, 4 infants had normal GMs which remained normal after starting treatment. GM-quality improved in 8 of 12 initially abnormal infants (Mc Nemar; $P=0.008$ ), whilst MOS slightly increased: median $10.5,12.0$ and 12.5 on days 0,1 and 7 , respectively (NS). Cumulative DXM doses, treatment duration and postnatal ages at starting DXM were not associated with change in GM-quality. Infants whose GMs improved were ventilated for a shorter period than infants whose GMs remained the same quality $(P=0.065)$.

Conclusions GM-quality did not deteriorate after DXM treatment but rather improved in infants with initial abnormal GMs. Our findings suggest that neurological functioning until three months post term is not adversely affected after low-dose DXM.

\section{THE NEURODEVELOPMENTAL ASSESSMENT OF VERY LOW BIRTH WEIGHT INFANTS AT 4-6 YEARS OF AGE}

doi:10.1136/archdischild-2012-302724.1257
'N Kavas, ${ }^{1} A E$ Arısoy, ${ }^{2} A$ Bayhan, ${ }^{3 B}$ Kara, ${ }^{1} A$ Günlemez, ${ }^{\prime} G$ Türker, ${ }^{1} M$ Oruç, ${ }^{1} A S$ Gökalp. ${ }^{1}$ Neonatology; ${ }^{2}$ Pediatrics; ${ }^{3}$ Pediatric Neurology, Kocaeli University Medical Faculty, Kocaeli, Turkey

The major and minor neurodevelopmental morbidities among premature infants become an important issue because of the increase in the number of surviving premature newborns.

The Aim of this study was to examine the cognitive, neuromotor, emotional and behavioral outcomes of the premature newborns at 4-6 years of age born with very low birth weight and to investigate the relationship between neuromotor and neurocognitive development.

The neuromotor status of 68 children were evaluated according to Touwen neurological examination, 64 children were assessed using Stanford-Binet and Peabody Picture Vocabulary Test, 65 children using Strength and Difficulties Questionnaire and Vineland Adaptive Behavior Scale.

Three cases were already diagnosed and followed as CP. According to Touwen examination 28 (\%41.2) children were normal, 35 (\%51.5) had simple minor neurological dysfunction (MND), 2 (\%2.9) had complex MND. The mean IQ score was 90.1 10.9 . The rate of hyperactivity, behavioral problems and emotional problems were in order $\% 60, \% 33.8$ and $\% 53.8$. The children were diagnosed as having a delay of $14.9 \pm 10.6$ month for conducting, 10.6 \pm 8.6 month for daily activities, $10.7 \pm 11.5$ month for social competence and a delay of $6.3 \pm 10.2$ month for motor behavior. The cognitive and neuropsychological results of the 35 children with MND and 28 children with normal neuromotor status were compared. The children with MND had significanly lower mean IQ score, more delay for motor behavior and they were more hyperactive.

Majority of the children who were considered as normal had cognitive impairment, language, behavior/emotional and neuromotor problems in various degrees.

\section{HEARING IN PRETERM INFANTS WITH POSTNATALLY ACOUIRED CYTOMEGALOVIRUS INFECTION}

doi:10.1136/archdischild-2012-302724.1258

IJ Nijman, ${ }^{2 B G A}$ van Zanten, 'AKM de Waard, 'C Koopman-Esseboom, 'LS de Vries, 'MA Verboon-Maciolek. 'Neonatology, University Medical Center Utrecht; ${ }^{2}$ Otorhinolaryngology and Head \& Neck Surgery, Rudolf Magnus Institute of Neuroscience, University Medical Center Utrecht, Utrecht, The Netherlands

Background and Aims Long-term sequelae of breast milkassociated cytomegalovirus (CMV) infection in preterm infants are insufficiently evaluated. We studied the hearing of preterm infants with postnatal CMV infection within the first and second year of life.

Methods Preterm infants (GA<32wks) admitted to our NICU between 2003 and 2011, and diagnosed with CMV infection using CMV PCR of urine at 40wks were included. Congenital infection was excluded in all. Hearing was tested using auditory brainstem response $(A B R)$ in the neonatal period and during the first and second year of life. Neurodevelopmental outcome was estimated using the Griffiths mental developmental scale (GMDS) at 18 months.

Results Eighty-eight preterm infants were diagnosed with postnatal CMV infection of whom four were lost to follow-up. All infants had normal hearing in the neonatal period. ABR-tests were performed in $64 / 84(76 \%)$ infants during the first year of life (median corrected age 7 months, range 2-11) and in 18/84 (21\%) infants during the second year (median corrected age 33 months, range 12-50). None of the infants developed SNHL. Mean GMDS score evaluated so far in 58/84 (69\%) infants at 15.8 months corrected age (range 13.0-21.0) was 104.4 (SD 9.9) and mean score of the language subscale was 16.7 months (SD 2.1). There were no differences in clinical data, cerebral ultrasonography results, viral load and GMDS scores between infants with hearing tests and non-tested infants. 
Conclusion Postnatally acquired CMV infection among preterm infants is not related with SNHL during the first and second year of life.

\section{GESTATIONAL AGE AND PREGNANCY DISORDERS AS RISK FACTORS FOR CEREBRAL PALSY}

doi:10.1136/archdischild-2012-302724.1259

${ }^{1} \mathrm{H}$ Trønnes, ${ }^{1} \mathrm{RT}$ Lie, ${ }^{2} \mathrm{~T}$ Markestad, 1,2D Moster. ${ }^{1}$ Department of Public Health and Primary Health Care; '2Department of Clinical Medicine, University of Bergen, Bergen, Norway

Background Both pregnancy disorders and low gestational age (GA) are associated with an elevated risk of cerebral palsy (CP). As many pregnancy disorders are associated with preterm birth, it is unclear whether the increased risk of $\mathrm{CP}$ in preterm children can be attributed to the pregnancy disorder or the low GA.

Aim To disentangle the risk of CP according to GA and pregnancy disorders in children born preterm.

Method Norwegian, national cohort study with linkage of the Medical Birth Registry of Norway to the Statistics Norway and the National Insurance Scheme. All births from 1967 to 2001 were followed through 2005, and 1,499,705 individuals were included in the cohort.

Results Placental abruption, chorioamnionitis, placenta previa, multiple birth, prolonged rupture of membranes, cervical conisation, unspecified bleeding and pre-eclampsia were associated with an increased risk of CP. The risk of CP increased with decreasing GA (23-27 wks RR 83.3 [95\% CI, 69.8-99.4], 28-30 wks RR 49.5 [95\% CI, 43.2-56.6], 31-33 wks RR 17.4 [95\% CI, 15.3-19.7], 34-36 wks RR 3.3 [95\% CI, 2.9-3.8]). The association between GA and CP was not substantially weakened after adjustment for pregnancy disorders.

Conclusion Although several pregnancy disorders were associated with an increased risk of CP, low GA appeared to be a more important risk factor for $\mathrm{CP}$ in preterm children.

\section{NEUROSENSORY OUTCOMES AND HEALTH CARE NEEDS IN SCHOOL-AGE CHILDREN BORN AT < 26 WEEKS' GESTATION AFTER ACTIVE PERINATAL CARE}

doi:10.1136/archdischild-2012-302724.1260

${ }^{1} \mathrm{~A}$ Faroogi, ${ }^{1} \mathrm{~A}$ Hautaniemi, ${ }^{2 B}$ Hägglöf, ${ }^{3} \mathrm{~F}$ Serenius. 'Dept of Pediatrics, Inst of Clinical Sciences, Umeå University; ${ }^{2}$ Child and Adolescent Psychiatry, Inst of Clinical Sciences, Umeå University, Umeå; ${ }^{3}$ Women and Child Health, Uppsala University, Uppsala, Sweden

Background and Aims To examine neurosensory outcomes and special health care needs in 10 to 16 -year-old extremely preterm (EPT) children born at 2 tertiary care centers in Sweden adhering to a policy of universal resuscitation of all infants born alive.

Design and methods The outcomes of 122 surviving EPT children were compared to a matched control of children born at term. Neurosensory impairments (NSI) were assessed by review of pediatric case records, intelligence by WISC-III, and functional limitations and special health care needs by validated parental interviews (QUICCC).

Results Of 213 consecutive EPT live births, 140 (66\%) survived to discharge home and 6 infants died in the first year of life. Of survivors, 122 children (91\%) were recruited for the study. Table1 shows rates of disabilities. EPT children had significantly higher rates of functional limitations and special health care needs than controls but the vast majority was free from severe disability that curtail them from activities of daily life.
Abstract 1260 Table 1 Rates of Disability

\begin{tabular}{lll}
\hline Disabilty & EPT (N = 121) & Control (N= 100) \\
\hline None & $45.4 \%(55)$ & $90 \% * *$ \\
Mild & $28.9 \%(35)$ & $7 \%^{* *}$ \\
Moderate & $19.8 \%(24)$ & $3 \%^{* *}$ \\
Severe & $6.6 \%(8)$ & $0 \% *$
\end{tabular}

Severe Disability: Severe CP (inability to walk), Blindness (visual acuity $<20 / 200$ in better eye), or IO <-3 SD; Moderate disability, moderate CP (considerable difficulty in walking with or without appliances), deafness requiring bilateral aids or worse or $10-3 S D$ to $<-2 S D$; Mild disability; mild $\mathrm{CP}$ (walking with minimal limitation), or an I0 $-2 \mathrm{SD}$ to $<-1 \mathrm{SD}$; ${ }^{*} \mathrm{P}<0.05 ;{ }^{*}{ }^{*} \mathrm{P}<0.005$

Conclusions Disability rates and special health care needs remain high in EPT children, but have not increased since 1990s despite the marked increase in their survival.

\section{NEURODEVELOPMENTAL OUTCOME IN EXTREMELY PREMATURE INFANTS BORN IN SWITZERLAND BETWEEN 2000-2008, PRELIMINARY DATA OF THE SWISS NEONATAL NETWORK}

doi:10.1136/archdischild-2012-302724.1261

'LJ Schlapbach, ${ }^{2} \mathrm{M}$ Adams, ${ }^{3} \mathrm{M}$ Aebischer, ${ }^{4} \mathrm{~B}$ Latal, ${ }^{5} \mathrm{~S}$ Grunt, ${ }^{6} \mathrm{C}$ Borradori-Tolsa, ${ }^{7} \mathrm{M}$ Bickle-Graz, ${ }^{2} \mathrm{HU}$ Bucher, ${ }^{2,4} \mathrm{G}$ Natalucci, for the Swiss Neonatal Network \& FollowUp Group. . Pediatric Critical Care Reasearch Group, Mater Children's Hospital, Brisbane, Australia, Brisbane, OLD, Australia; 'Division of Neonatology, Zurich University Hospital, Zurich; ${ }^{3}$ Pediatric Intensive Care Unit, Department of Pediatrics, Bern University Children's Hospital, Bern; ${ }^{4}$ Child Development Center, Zurich University Children's Hospital, Zurich; ${ }^{5}$ Department of Neuropaediatrics, Bern University Children's Hospital, Bern; ${ }^{6}$ Division of Development and Growth, Geneva University Children's Hospital, Geneva; 'Department of Child Development, CHUV Lausanne, Lausanne, Switzerland

Introduction So far, national outcome data on extremely premature infants in Switzerland were not available, and discussions on the care of these patients were based on earlier studies from other countries. This national study assessed neurodevelopment in Swiss infants born between 2000 and 2008 at $240 / 7$ to $276 / 7$ weeks gestational age.

Methods Neurodevelopment was assessed at 2 years using the BSID II. Moderate neurodevelopmental disability (ND) was defined as a mental (MDI) or psychomotor (PDI) development index of $55-70$, or mild cerebral palsy (GMFCS level 2). Severe ND was defined as a MDI or PDI $<55$, cerebral palsy (GMFCS level $\geq 3$ ), deafness or blindness. Multivariate logistic regression was performed.

Results Among the 1147 extremely preterms born during the study period 303 (26\%) died. Follow-up information was available in $684(81 \%)$ survivors. 440 (64\%) showed normal development, 166 (24\%) moderate ND, and $78(12 \%)$ severe ND. Severe ND was significantly $(\mathrm{p}<0.05)$ associated with earlier year of birth, major intracerebral lesions, bronchopulmonary dysplasia, grade 3 retinopathy of prematurity, and lower socioeconomic status. In contrast, birth weight, gestational age and sex showed only trendwise associations with severe ND.

Conclusion Based on these preliminary analyses, we now are ready to establish representative Swiss national data on the outcome of extremely premature infants. These will offer guidance to obstetricians, neonatologists, neurologists and parents based on Swiss data.

\section{PREVALENCE OF HEARING IMPAIRMENTS AT AGE FOUR YEARS IN EXTREMELY PRETERM INFANTS}

doi:10.1136/archdischild-2012-302724.1262

'A Grahn, 'S Horsch, 'B Skiöld, 'M Blennow, 2 Uhlén, 'B Hallberg. 'Neonatology: ${ }^{2}$ Audiology, Karolinska Institutet and University Hospital, Stockholm, Sweden 